Paidéia, 2001, 11(20), 79-84

\title{
DAS BRUXAS, DOS ÍNDIOS, DOS NEGROS E DOS JOVENS DA FEBEM
}

\author{
Sylvia Leser de Mello ${ }^{2}$ \\ Universidade de São Paulo
}

\begin{abstract}
RESUMO: Este artigo visa discutir os temas Pesquisa e Direitos Humanos, partindo da definição do que pretende a Ciência, suas limitações e momentos seus a serviço de condenações de bruxas e ateus. Trata-se de levantar a questão da 'parcialidade' da Ciência e das formas de exclusão que ela ajudou a gerar e manter face aos criminosos, aos loucos, aos negros e, sem dúvida, aos jovens das camadas populares que são institucionalizados na FEBEM. E, na tentativa de resistência a se deixar levar pelo que de nefasto existe na mercantilização da Ciência hoje, buscar radicalizar a exigência de defesa dos Direitos Humanos.
\end{abstract}

Palavras-Chave: Pesquisa; Parcialidade/Mercantilização da Ciência; Direitos Humanos

\section{WITCHS, INDIANS, BLACK PEOPLE AND YOUNG PEOPLE OF FEBEM}

\begin{abstract}
This article intends to discuss the subjects of Research and Human Rights; it begins with the identification of the objectives of Science, its limitations and times when she was helping to condemn the witchs and atheists. It is called attention to the problem of Science partiality and to the ways of exclusion that she helped to create and support in respect to criminals, fools and black people, but also to young people of popular classes institutionalized in FEBEM. To attempt to resist to the bad consequences of Science mercantilization of nowadays, it is important to radicalize the exigency in the defense of Human Rights.
\end{abstract}

Key words: Research; Commercial and Partiality Science; Human Rights

Cultivar o deserto como um pomar às avessas. João Cabral de Melo Neto

O tema proposto para discussão trata da Pesquisa e dos Direitos Humanos e para falar de relações tão amplas quanto são aquelas que se podem estabelecer entre esses dois elementos, optou-se por buscar exemplos e respostas que possam facilitar a transformação das reflexões em prática efetiva e não só oferecer considerações abstratas ou meramente retóricas. Como outros conceitos fundamentais para a vida em sociedade, como o de Democracia, os Direitos Humanos só podem sair do contexto abstrato e universal em que foram concebidos na concretude do cotidiano e de sua prática.

É muito possível conceber a justiça das pro-

\footnotetext{
${ }^{1}$ Artigo recebido para publicação em 12/2000; aceito em 06/ 2001

2 Endereço para correspondência: Sylvia Leser de Mello, Instituto de Psicologia da USP, Avenida Prof. Mello de Moraes, 1721 - São Paulo Cep 05508-900. E-mail: leserdemello@aol.com
}

posições de uma legislação altamente avançada, como o Estatuto da Criança e do Adolescente e, no entanto, não conseguir visualizar sua aplicação nos recentes episódios envolvendo os jovens da Febem. É necessário mais do que as palavras para expressar essa dificuldade. Quando se trata de Direitos $\mathrm{Hu}-$ manos, as nossas dificuldades se inscrevem, em geral, nesse espaço, que vai da palavra da lei à vida de todo o dia ou do conceito à prática.

Para poder situar, não vamos agora falar da Febem, mas da Pesquisa e da Ciência e em que limites tangenciam os Direitos Humanos.

O propósito da Ciência é conhecer, ou seja, obter a certeza teórica sobre o funcionamento e causas dos fenômenos de modo a permitir a previsibilidade e a intervenção no mundo dos acontecimentos. Para tanto, a Ciência criou modos de proceder, denominados métodos, que cercam de cuidados objetivos o estudo dos fenômenos, utilizando medidas de espaço e tempo, que têm por fim o controle das circunstâncias em que aqueles ocorrem.

A Ciência e o espírito científicos, nessa 
acepção, nasceram com o mundo moderno. Por meio da Ciência e da Tecnologia o homem modificou de tal maneira o seu habitat, procurando eliminar qualquer vestígio da imponderabilidade da natureza, de modo que já há muito pouco de "natural" neste habitat e no mundo do artifício humano onde decorre a nossa vida. $O$ presente que vivemos é uma demonstração indiscutível da potencialidade criadora do conhecimento, da Ciência.

A Psicologia, ainda que em pequena escala, também se dispôs a conhecer, a ter certeza sobre o desenrolar dos fenômenos, a prever e intervir sobre eles. Mas há dificuldades peculiares ao conhecimento psicológico, pois, a Psicologia possui uma ambigüidade que se pode expressar na pergunta seguinte: o homem é máquina biológica complexa ou fabricante de cultura e de símbolos, criador da história? Uma boa resposta seria aquela que partisse da duplicidade de nossa natureza, não para entregar a Psicologia ao sono apaziguante da Biologia, que nos desresponsabiliza por nossas próprias ações, mas por nos permitir encontrar um lugar melhor de onde possamos pensar e falar sobre os homens. Para a Psicologia Social, que é a minha referência, o homem é criador de cultura e de história. Fora desse enquadramento podemos entender como funciona a fisiologia do olho mas não o olhar. Também a Sociologia se dispunha, em seus inícios, a orientar a vida humana em comunidade de acordo com leis racionais. As conquistas de ambas foram modestas nesse sentido. Mas elas partilharam da comum arrogância que acompanha a vitória da Ciência sobre a natureza e cujas conseqüências são dia a dia mais visíveis na destruição sistemática e impiedosa das outras formas de vida que conosco compartilham a mesma terra, e do ambiente que compartilhamos com elas.

Os resultados das Ciências Humanas, no que diz respeito ao avanço do conhecimento do homem sobre si mesmo, deixam muito a desejar. A vida quotidiana está cada vez mais difícil para um número maior de pessoas e a tecnologia não aliviou nossa carga de infelicidade, de exploração e de violência encerrada nas relações dos homens entre si. Aquelas perguntas essenciais, que estão presentes desde que os homens reconheceram que a sua consciência é o espelho do mundo para eles, estão aparentemente esquecidas. Quem sou, o que sou, para onde vou são questões cujas respostas variaram desde a mais simples veneração dos deuses até a mais anti-metafísica filosofia - o materialismo histórico. Embora desdenhadas pela Psicologia, são perguntas que se renovam a cada nascimento de uma criança.

Não desejo deixar a impressão de que estou levando em conta apenas o poder destrutivo da Ciência. No início desta corrida maluca que apostamos agora com a tecnologia, Freud já dizia que é excelente poder falar com o filho, que se encontra a quilômetros de distância, através do telefone, mas se não houvesse o trem, para levá-lo tão longe, e tão depressa, o telefone seria desnecessário. Sem chegar à radicalidade do velho mestre penso que uma desconfiança nas maravilhas do mundo moderno é sempre saudável e um pouco de ceticismo sobre as virtudes da Ciência e seu valor para a vida humana também seria bem vindo. ${ }^{3}$

Há um outro aspecto relativo agora às Ciências Humanas e que precisa ser ressaltado. Nem sempre os resultados de pesquisas e trabalhos nessas áreas vêm acrescentar alguma coisa ao conhecimento. Profundamente marcadas pela sua inserção em domínios muito próximos da ideologia e da política, o caráter histórico e transitório de seus pressupostos pode gerar preconceitos.

Parece que afirmar a possibilidade de gerar preconceitos a partir de pressupostos de algumas das teorias em Ciências Humanas é propor um paradoxo, porque a natureza do preconceito é antagônica à natureza da Ciência, do conhecimento. $\mathrm{O}$ preconceito é fruto do julgamento apressado, carregando grande dose de irracionalidade. A Ciência está em busca da verdade e o preconceito é a negação desta busca.

Nas Ciências ditas "Naturais" os equívocos nos pressupostos sobre as leis que regem a matéria são visíveis nos resultados, mesmo que isso tome algum tempo, ou causem mesmo resultados nefastos. Na prática médica, há exemplos notáveis. Muitos ainda sofrem as conseqüências da Talidomida e não são poucos os procedimentos médicos ou pro-

\footnotetext{
"Vale a pena rever o estudo do ceticismo e também o de Husserl que retoma a noção de epoché, dos cépticos, a suspensão do juízo afím de "limpar" a consciência dos vestígios do chamado "mundo natural" tão valorizado pelo positivismo.
} 
dutos da indústria farmacêutica cujos resultados poderão vir a ser perigosos para nós.

Nada pois de espetacular existe no caso das Ciências Humanas. A natureza mesmo do objeto a ser investigado, por ser mais elusiva, infinitamente plástica e dificilmente fixável, transforma equívocos em modos normativos de pensar os homens e a sociedade. O conhecimento significa poder, e o serviço que certos modos de pensar prestam ao exercício do poder social transformam-nos em "verdades" que o próprio poder torna inquestionáveis.

Alguns exemplos são dramáticos. A crença antiga em espíritos que se moviam no espaço, acrescida do terror que o demônio medieval cristão inspirava, deu origem a um conjunto de "conhecimentos", usados durante séculos pela inquisição (Ginsbrug, 1988; 1991) Desse saber se apossavam pequenos magistrados em pequenas aldeias ou juízes que, atemorizados pela Inquisição, infligiam penas terriveis às pessoas que, segundo provas fornecidas pela Ciência, possuíam pacto com o diabo, as ditas bruxas. Um tempo prolongado de estio, uma doença que atacava os animais ou as pessoas, detonavam uma procura por responsáveis pela desdita, que sempre eram encontrados no âmbito das relações humanas. Grande parte das vítimas da sangrenta procura de bruxas, era constituída dos excluídos sociais da época: camponesas pobres, saltimbancos, mendigos, pessoas velhas e solitárias de hábitos esquisitos e assim por diante. Muitas, depois de acusadas, passavam a crer no que lhes era imposto e descreviam, com detalhes, as circunstâncias dos pacto.(Carlini, 1966). ${ }^{4}$

Hoje podemos dar de ombros ou sorrir afirmando que eram fanáticos religiosos e não cientistas que assim procediam. Nada mais errado. Esta era a ciência oficial da época, e há tratados eruditos que provam a natureza demoníaca da bruxa que só poderia ser purificada com fogo. Um deles, o mais famoso, o Malleus Malleficarum (O Martelo das Bruxas), foi escrito para ensinar métodos científicos de

${ }^{4}$ Há uma extensa bibliografia sobre as bruxas e as feiticeiras, que pode ser encontrada em Michael Kunze (1989). A Caminho da Fogueira, RJ: Ed. Campus. e Robert Mandrou (1979). Magistrados e Feiticeiros na França do século XVII. SP: Perspectiva. A Inquisição também andou pelo Brasil e incomodou até mesmo nosso padre Vieira. Há uma obra interessante sobre um ex-colono brasileiro condenado pelo Santo Off́cio em 1741. Plínio Freire Gomes (1997). Um Herege vai ao Paraíso. SP: Cia das Letras. reconhecimento dos servos do demônio. Os procedimentos não eram aleatórios, mas derivavam de um modo de agir, bastante codificado, que conduzia 0 processo dos acusados de maneira estritamente científica. Não se duvidava das confissões que eram obtidas durante a tortura que as pessoas acusadas sofriam. A própria tortura possuía um caráter ritualizado: havia uma ordem metódica nos procedimentos, graduando a dor e o sofrimento de forma a obter a "verdade" dos acusados. Em Voltaire encontramos um belo exemplo da eficácia política do massacre ritual - os autos de fé - após o terremoto de Lisboa, contado pelo incurável otimista Cândido: "Após o tremor de terra (dez. 1755) que destruíra três quartos de Lisboa, não descobriram os sábios do país melhor recurso para prevenir a ruína total, do que oferecer ao povo um belo auto-de-fé; decidira a Universidade de Coimbra que o espetáculo de algumas criaturas queimadas a fogo lento, em grande cerimônia, é segredo infalível para impedir a terra de tremer." (Voltaire, 1964, p. 31)

E nem é preciso tratar-se do demônio para encontrar os efeitos perversos dos conhecimentos científicos. Assim como as bruxas, índios e negros foram perseguidos por noções científicas a serviço do poder. A história da conquista do Novo Mundo está carregada de exemplos de teorias formuladas por acadêmicos. O que faziam, na verdade, era oferecer a imagem dos países colonizadores, Espanha e Portugal, "como autênticas potências cristãs convencidas (..), da superioridade de sua religião e cultura sobre os bárbaros ameríndios, mas que haviam em larga instância, atuado no interesse dos seus súbditos e da cristandade universal. " dizimando populações inteiras. (Pagden, 1993; Todorov, 1993) ${ }^{5}$. E em seguida, a brutal história dos negros, submetidos ao tráfico de escravos e ao cativeiro em terra estranha. Segundo, os textos da época mostram que eles possuem incrível resistência à dor e à fadiga porque sua natureza não é plenamente humana. Rapidamente tratou-se de confirmar a semi-humanidade dos negros através de provas científicas, que garantiam sua força bruta e pouca inteligência ${ }^{6}$. A ci-

\footnotetext{
'Talvez uma das mais sensiveis descrições dos procedimentos dos espanhóis em relação aos conquistados.

- A famosa pesquisa que se denominou a Curva do Sino traz de volta a mesma expectativa de justificar cientificamente a exclusão dos negros e dos pobres em geral.
} 
ência justificou e deu aval à prática iníqua que condenou milhões de homens e mulheres à escravidão. Uma vez obrigados pela violência da coerção a exercerem os mais pesados trabalhos recebendo parca alimentação e nenhum cuidado, apenas os mais fortes sobreviviam, justificando as previsões da ciência, assim como as mulheres acusadas de satanismo acabavam revelando práticas satânicas.

Ainda mais próximo de nós, o famoso método científico do psiquiatra italiano Lombroso, permitia identificar o criminoso nato, o criminoso que já o era até mesmo antes de nascer, baseado em medições precisas dos ossos da cabeça e em proporções entre o corpo e a cabeça e no formato das orelhas da boca e do nariz. Lombroso propunha-se a criar uma criminologia científica, com base numa tipologia minuciosa que permitiria prever o comportamento dos indivíduos, decidir, portanto, a priori, sem julgamento, se um dado cidadão era ou não um criminoso.

Bem perto de nós, lidando com a nossa área de especialidade, a subjetividade, muita violência foi feita em nome da ciência e do conhecimento no tratamento e caracterização dos chamados loucos.

É bom, como um parêntesis lembrar que a exclusão sempre se fez acompanhada de justificativas que afirmavam princípios de sanidade mental no caso dos loucos e /ou princípios de ordem social no caso de outros excluídos - os vagabundos, os mendigos, os subversivos ${ }^{7}$. E até mesmo aqueles que não concordam, e nas palavras de Goffman (1973), não querem ficar no seu lugar

Sabe-se que a ciência criminológica fundada por Lombroso, com suas medidas e proporções, foi realizada a partir de pesquisas com detentos que pertenciam, em grande maioria, ao campesinato pobre da Itália. Ao definir o que chamou de criminosos natos segundo os traços daqueles detentos, e ao encontrar regularidade e uniformidade em suas medidas antropométricas, Lombroso promoveu a estigmatização das classes camponesas italianas. Do mesmo modo, se fôssemos hoje realizar este tipo de estudo com os nossos presos descobriríamos que os negros são mais propensos ao crime, uma vez que sofrem maior perseguição das fontes repressoras e são punidos mais freqüentemente e com maior rigor pelos juízes do que brancos acusados dos

\footnotetext{
${ }^{7}$ Nem é preciso lembrar A História da Loucura de Michel Foucault
}

mesmos delitos. ${ }^{8}$

Se alguns trabalhos já fizeram a crítica dos preconceitos criados a partir do uso dos testes de inteligência, dos diagnósticos e laudos emitidos sobre crianças e jovens,,. há ainda muito a ser feito para continuar demonstrando que o conhecimento pode ser ideologia e que é tão histórico quanto os homens que o elaboraram.

A parcialidade das "verdades" da Ciência pode ser vista até mesmo na Física, paradigma de todos os modelos de conhecimento que se dizem científicos. Os pesquisadores da física defrontaram-se com a idéia de caos, após séculos da crença na regularidade e no determinismo das leis de Newton. O indeterminismo é hoje necessário para explicar certos fenômenos de que a ordem newtoniana não dá conta. A conclusão de que a ordem e a regularidade dos fenômenos não são categorias inerentes a eles, mas podem ser, kantianamente, atributos do nosso olhar sobre eles, revolucionou as concepções universalistas da ciência. Também é preciso conhecer a desordem.

No caso das Ciências Humanas o sujeito é o introdutor da desordem e do indeterminado. Quando ele irrompe na cena do pensamento racional, é para ser pensado sob a ótica da determinação. É necessário tecer uma rede de micro poderes, disciplinar o corpo humano e o corpo social, preparar o olhar para manter o espaço esquadrinhado, dividido e tornado a dividir, de modo que tudo seja visto pelos olhos vigilantes do poder. Em seguida, as disciplinas permitem modelar corpo e espírito, ofertar identidades consentidas e destinos previsíveis. ${ }^{10}$

No entanto, a Sociologia descobre a violência atrás da ordem, a repressão atrás do consenso, a irracionalidade na modernização técnica e o interesse privado nos princípios gerais que governam o coletivo. A Psicologia se vê às voltas com o inconsciente, o imprevisível, o inclassificável, o caótico. Apesar de suas amarras históricas ${ }^{1}{ }^{1}$ o sujeito não é determinado, é livre.

\footnotetext{
${ }^{8}$ Pesquisa realizada pelo Núcleo de Estudos da Violência da USP com a Fundação SEADE, sobre a delinquiência juvenil, junto às cortes de justiça de menores, em São Paulo, mostra com muita clareza essa tendência da justiça.

" Ver o v.8 n'. 1 da Revista Psicologia USP - "Psicologia e Razão Instrumental" dedicada a essa discussão.

${ }^{10}$ Uma vez mais, Michel Foucault em Vigiar e Punir.

11 "Preso à minha classe e a algumas roupas..." como diz o poeta Carlos Drummond de Andrade
} 
Para lidar com a ordem e a desordem, com o singular e o plural, com o semelhante e o dessemelhante voltam a ser postos problemas metodológicos. Busca-se apoio na Epistemologia para dar conta da diversidade no interior da homogeneidade.

Uma das mais importantes conquistas da descoberta do sujeito e de sua liberdade, é o estudo do quotidiano que redimensiona o seu lugar histórico e cognitivo.

O quotidiano é a dimensão do sujeito. O sujeito do quotidiano é o sujeito total, assim como a totalidade dos sujeitos vive imersa no quotidiano. O quotidiano remete à idéia da desordem, de fragmentação, porque o seu presente contínuo não permite a reflexão, exige o ato impensado, habitual e mecânico. Não há fixação do momento presente, ele está em fluxo permanente. Nessa luta constante em que o sujeito é impelido pelo passado para um devir que tende a devorá-lo, ele é obrigado a construir, para enfrentar o futuro, uma noção de permanência, centrada, em geral, em si mesmo. Nesse sentido ele precede a criação da realidade social que também adquire substância e continuidade a partir da consciência reflexiva do sujeito, portanto sujeito cognoscente.

Nessa medida, o senso comum recupera seu valor documental. Não se nega mais ao sujeito o conhecimento sobre si mesmo e sua circunstância, como a busca aos fatos objetivos havia determinado. A desconfiança na subjetividade eliminava a subjetividade. Presumia-se que os sujeitos não eram capazes de dar conta do significado de suas próprias vidas. $O$ estudo do quotidiano, pelo contrário, exige a presença psicológica deles.

Os homens participam duplamente, pois, da construção da história: em sua construção material e na reconstrução simbólica a que submetem o material fragmentário de sua experiência quotidiana, por meio da consciência. Esta faz parte do mundo e com ele está comprometida. Para obter a constância na minha própria impressão de mim, devo ser capaz de estar unida à constância que, a partir da minha, reencontro no mundo.

Não há, porém uma hegemonia da consciência, impondo sua forma à realidade. Há homens reais e concretos que não possuem só consciência ou corpo mas são consciência e corpo que experimen- tam e transformam a realidade concreta. Reduzir a consciência a coisa ou a coisa à consciência são as marcas de explicações psicológicas mergulhadas no positivismo.

A Ciência constrói, através do método, um modo de ver o mundo. Ela é parte do poder, pode ser apropriada e por si só é poderosa. Como trabalha com palavras, suas definições estão mais próximas do senso comum e podem ser transformadas facilmente em instrumento de dominação. Barthes (1989) dizia que "o poder é o parasita de um organismo trans-social, ligado à história inteira do homem e não somente à sua história política, histórica. Esse objeto em que se inscreve o poder, desde toda eternidade humana, é : a linguagem - ou, para ser mais preciso, sua expressão obrigatória: a língua. (....) Por outro lado, os signos de que a língua é feita, os signos só existem na medida em que são reconhecidos, isto é, na medida em que se repetem; o signo é seguidor, gregário; em cada signo dorme este monstro: um estereótipo: nunca posso falar senão recolhendo aquilo que se arrasta na língua." (p.12) Estigma e preconceito são uma combinação do poder simıbólico do signo "que se arrasta na língua" e do poder político da palavra.

Depois de todo este discurso - palavras, palavras - quero retornar à Febem, à problemática da criança, do jovem e à infamante palavra menor.

De modo geral, violamos, em nosso país, todos os direitos da criança promulgados pela ONU em 1959 e a nossa própria legislação contida no ECA.

Não violamos só em atos- vide a violência doméstica, a violência da pobreza e do trabalho infantil, o morticínio dos jovens nas nossas periferias urbanas e outros espetáculos semelhantes aos quais nos acostumamos. Violamos também em palavras, ofendendo e desqualificando com o uso de qualificativos degradantes, como menor ou carente. $\mathrm{Ou}$ mesmo, quando nossas pesquisas definem os futuros delinqüentes, à maneira de Lombroso, ou atribuem a culpa pelo fracasso moral dos jovens exclusivamente às suas famílias.

Tentando organizar algumas idéias e procurando fugir de estereótipos e lugares comuns, cheguei à conclusão de que é difícil falar de crianças e adolescentes sem repetir inumeráveis chavões ou cair na vala larga do preconceito A infância e a juventude 
são temas preferidos da modernidade burguesa. A concepção da infância como uma das estações da vida, alegre e despreocupada, com seus folguedos e sua liberdade, e a juventude como o tempo da experimentação e da turbulência, ambos definidos como períodos da inteligência e da espontaneidade generosa, essa concepção está por trás dos meus olhos e da minha mente quando vou pensar e pesquisar. No entanto, ela está marcada pela história e pela posição de classe, longe do valor universal que a ela se quer atribuir. Essa concepção é normativa, diz o que deveria ser e não como é, de fato, vivida a infância e a juventude para a grande maioria dos jovens no Brasil.

De volta à Febem, e considerando que não quero dar abrigo aos preconceitos e que é preciso resistir à Ciência que às vezes é a sua porta-voz, precisamos perguntar qual é a imagem de jovem que deve servir de norte à pesquisa?

Se quiser ter os Direitos Humanos como um horizonte sempre presente, devo optar pelas imagens da extremada violência que pudemos presenciar e que se exerce sobre os jovens? A violência de que os jovens ficam reféns, presos na cruel circularidade da vítima e do réu? Devo servir-me de Lombroso? Devo encontrar naqueles jovens a mais pura expressão de uma síndrome anti-social? Ou poderíamos partir da premissa da alteridade, talvez até de uma alteridade quase tão radical quanto aquela com que se depararam os europeus ao chegarem na América?

A pesquisa decorre das premissas teóricas. Se não posso tomar o homem como objeto - ele é sempre sujeito - minha pesquisa tem que necessariamente ser o que Sartre denomina "uma relação entre homens". Porém a condição humana de portador e construtor da história não nos permite capturá-lo sem mediações. Do meu ponto de vista, as mediações são as instituições, compreendidas como práticas intersubjetivas, que podem e são experimentadas como reais, como objetivas, mas que só se tornam legítimas na consciência compartilhada por todos os membros de um grupo. Não é a metodologia quantitativa ou qualitativa que define as relações que se estabelecem entre pesquisador e pesquisado, mas o reconhecimento de que na outra ponta do questionário, ou do teste, ou do gravador há um sujeito, com tudo o que isso significa: um semelhante, mesmo na diferença, portador de direitos e de cidadania- inclu- sive do direito de saber para que está sendo pesquisado, um indivíduo único, livre e capaz de ação livre cuja palavra tem, em princípio, o mesmo valor que a daquele que investiga.

O que transforma o sujeito em objeto é vê-lo como coisa, tão manipulável como uma máquina, não como a finalidade do conhecimento mas o meio para fins que nem sempre são muito claros. Um dos grandes riscos que a Ciência corre é ser totalmente submersa na busca de financiamentos e de prestígio para o cientista. Num mundo de negócios, também a Ciência se negocia e se transforma em mercadoria. No mundo das mercadorias, já dizia Marx, a primeira a se subverter é a relação entre os meios e os fins.

Resistir à aproximação da pesquisa à mercadoria ou do saber com o mercado transformou-se hoje numa necessidade, dada a virulência do mal mercantilizante que atinge as instituições de país sem exclusão dos centros de pesquisa. Radicalizar as exigências que a defesa dos Direitos Humanos nos colocam talvez não seja uma posição muito cômoda. Ainda assim, devemos algo às vítimas do passado, quanto mais não seja, praticar o exercício da denúncia quando novas vítimas se vêem ameaçadas.

Referências Bibliográficas

Barthes, R. (1989). Aula. São Paulo: Cultrix

Carlini, F. (1966). Magia e Bruxaria na Idade Média e no Renascimento. Psicologia, $v 7, \mathrm{n}^{\circ} 12$.

Ginsburg, C. (1988). Os andarilhos do Bem. São Paulo: Cia das Letras

Ginsburg, C. (1991). História Noturna. São Paulo: Cia das Letras

Goffman, E. (1973). La mise en scène de la vie quotidienne. Pari: Les Éditions de Minuit.

Kramer, H. \& Sprengler, J. (1973). Le marteau des Sorcières. Paris: Danet

Pagden, R (1993). La caida del hombre natural. Madri: Alianza Editorial

Todorov, T. (1993). A conquista da América. São Paulo: Martins Fontes

Voltaire, (1964). Candido ou o Otimismo. Rio de Janeiro: Civilização Brasileira. 